\title{
Effectiveness of Hypochlorous Acid to Reduce the Biofilms on Titanium Alloy Surfaces in Vitro
}

\author{
Chun-Ju Chen ${ }^{1}$, Chun-Cheng Chen ${ }^{2,3, *}$ and Shinn-Jyh Ding ${ }^{1,2,3, *}$ \\ 1 Institute of Oral Science, Chung Shan Medical University, Taichung City 402, Taiwan; \\ ccz1001@yahoo.com.tw \\ 2 School of Dentistry, Chung Shan Medical University, Taichung City 402, Taiwan \\ 3 Department of Dentistry, Chung Shan Medical University Hospital, Taichung City 402, Taiwan \\ * Correspondence: fw3256@yahoo.com.tw (C.-C.C.); sjding@csmu.edu.tw (S.-J.D.); \\ Tel.: +886-6-2471-8668 (ext. 55255) (C.-C.C.); +886-6-2471-8668 (ext. 55529) (S.-J.D.)
}

Academic Editor: Ihtesham ur Rehman

Received: 13 April 2016; Accepted: 15 July 2016; Published: 19 July 2016

\begin{abstract}
Chemotherapeutic agents have been used as an adjunct to mechanical debridement for peri-implantitis treatment. The present in vitro study evaluated and compared the effectiveness of hypochlorous acid $(\mathrm{HOCl})$, sodium hypochlorite $(\mathrm{NaOCl})$, and chlorhexidine $(\mathrm{CHX})$ at eliminating Gram-negative (E. coli and P. gingivalis) and Gram-positive (E. faecalis and S. sanguinis) bacteria. The effect of irrigating volume and exposure time on the antimicrobial efficacy of $\mathrm{HOCl}$ was evaluated, and a durability analysis was completed. Live/dead staining, morphology observation, alamarBlue assay, and lipopolysaccharide (LPS) detection were examined on grit-blasted and biofilm-contaminated titanium alloy discs after treatment with the three chemotherapeutic agents. The results indicated that $\mathrm{HOCl}$ exhibited better antibacterial efficacy with increasing irrigating volumes. $\mathrm{HOCl}$ achieved greater antibacterial efficacy as treatment time was increased. A decrease in antimicrobial effectiveness was observed when $\mathrm{HOCl}$ was unsealed and left in contact with the air. All the irrigants showed antibacterial activity and killed the majority of bacteria on the titanium alloy surfaces of biofilm-contaminated implants. Moreover, $\mathrm{HOCl}$ significantly lowered the LPS concentration of $P$. gingivalis when compared with $\mathrm{NaOCl}$ and $\mathrm{CHX}$. Thus, a $\mathrm{HOCl}$ antiseptic may be effective for cleaning biofilm-contaminated implant surfaces.
\end{abstract}

Keywords: dental implant; hypochlorite acid; antiseptics; antimicrobial activity

\section{Introduction}

The use of dental implants to replace missing teeth has provided predictable and good long-term results [1-4]. However, the incidence of short- and long-term complications has increased. The two most common reasons for implant failure are overloading and infection. It is generally accepted that microbial biofilms play a significant role in the development of peri-implant diseases $[5,6]$. When the pristine surface of a dental implant is exposed to the oral cavity following installation, bacterial colonization takes places in a manner similar to that of teeth, which in turn gives rise to the development of mature biofilms [7,8]. Removal of the bacteria and their byproducts, such as LPS, has proven problematic [9] because of the screw-shaped design and surface microstructure of implants. Mechanical debridement alone is incapable of removing all biofilms. In addition, implants with rough surfaces and a large surface free energy tend to accumulate more plaque [10]. Infections are difficult to eliminate because the initial bacterial adhesion starts in areas of high wettability and inside the pits and grooves of the roughened surfaces [11]. Thus, the use of different chemotherapeutic agents has been proposed for the treatment of infected implant surfaces. To decrease the number of microorganisms to a level compatible with periodontal health, clinicians often use antimicrobial agents, such as $\mathrm{CHX}, \mathrm{NaOCl}$, 
citric acid, hydrogen peroxide, and tetracycline paste, as an adjunctive treatment to mechanical debridement [12-14]. However, satisfying therapeutic strategies or scientifically based treatment recommendations remain unavailable [14].

The use of high doses of an antimicrobial agent is effective at eradicating bacteria. Zablotsky et al. found that among the antiseptics tested for treating contaminated titanium surfaces, citric acid resulted in the lowest amounts of residual LPS when compared with the saline control; however, these differences failed to reach statistical significance [9]. Dennison et al. studied decontamination treatments for LPS (from P. gingivalis)-contaminated machined and titanium plasma-sprayed (TPS) implants using deionized water, citric acid solution, and 0.12\% CHX [15]. The citric acid and CHX treatment presented no statistically significant differences in antibacterial effectiveness on machined and TPS surfaces when compared with deionized water. Commonly used antiseptics are effective at killing microorganisms but not removing biofilm on titanium implants [13]. Biofilms are heterogeneous structures that have a high resistance to antimicrobial agents [16].

In addition to the aforementioned antiseptics, $\mathrm{HOCl}$ has attracted attention. $\mathrm{HOCl}$ is generated by the body's immune cells to fight invading pathogens and infection [17]. At an effective antimicrobial concentration range, $\mathrm{HOCl}$ is non-irritating and non-sensitizing because of its lower cytotoxicity to mammalian cells when compared with $\mathrm{NaOCl}$ and $\mathrm{H} 2 \mathrm{O} 2$ [18]. In dental treatment procedures, a mild acidic $\mathrm{HOCl}$ solution is introduced as an endodontic irrigating solution [19] and as a chemotherapeutic agent for the treatment of periodontitis [20]. However, a search of the literature shows a paucity of articles addressing the effects of $\mathrm{HOCl}$ as a treatment for bacterial growth on titanium implants. We hypothesized that $\mathrm{HOCl}$ would be effective at eradicating bacteria on implant surfaces in vitro. Accordingly, the purpose of the present study was (1) to examine the effectiveness of $\mathrm{HOCl}$ at different irrigating volumes and treatment times at eliminating Gram-positive and Gram-negative bacterial strains; and (2) compare the effects of $\mathrm{HOCl}, \mathrm{NaOCl}$ and $\mathrm{CHX}$ on biofilm-contaminated titanium alloy surfaces used as a model of peri-implantitis. Importantly, LPS concentrations remaining on the titanium alloy surfaces were examined because the biofilms inactivated/killed by irrigants may remain on the implant surface, which would facilitate subsequent microbial adhesion.

\section{Results}

\subsection{Antibacterial Effectiveness of $\mathrm{HOCl}$}

\subsection{1. $\mathrm{HOCl}$ Volume Effect}

Clinical significance is the practical importance of treatment efficacy. The antibacterial activity of $\mathrm{HOCl}$ at different volume ratios to bacterial suspensions of E. coli, P. gingivalis, E. faecalis, and S. sanguinis is shown in Figure 1. As expected, the antibacterial ability of $\mathrm{HOCl}$ against the four strains was volume-dependent. Notably, the 4:1 volume ratio of $\mathrm{HOCl}$ to bacterial solution completely killed the bacteria. This result was similar to the effectiveness of $1.3 \% \mathrm{NaOCl}$ and $0.2 \% \mathrm{CHX}$ at a $1: 1$ volume ratio with a $30 \mathrm{~s}$ treatment time. The results of $1.3 \% \mathrm{NaOCl}$ and $0.2 \% \mathrm{CHX}$ were not shown because of undetectable absorbance values. As the treatment time increased, $\mathrm{HOCl}$ showed significantly greater antibacterial efficacy $(p<0.05)$. Based on these data, subsequent experiments used a 4:1 volume ratio of the irrigant $(\mathrm{HOCl}, \mathrm{NaOCl}$, and $\mathrm{CHX})$ to bacterial suspension. 
(a)

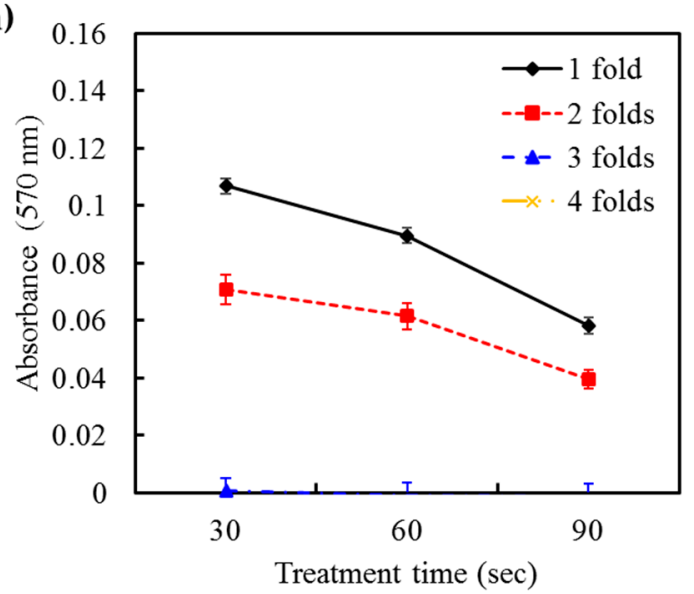

(c)

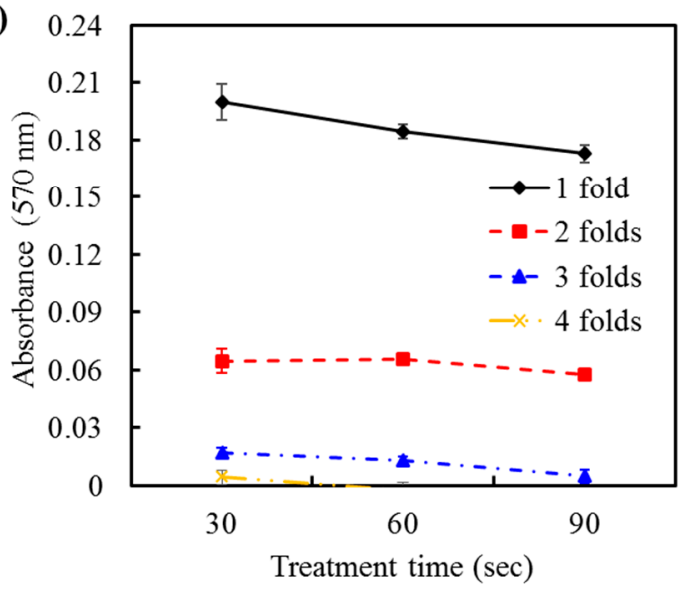

(b)

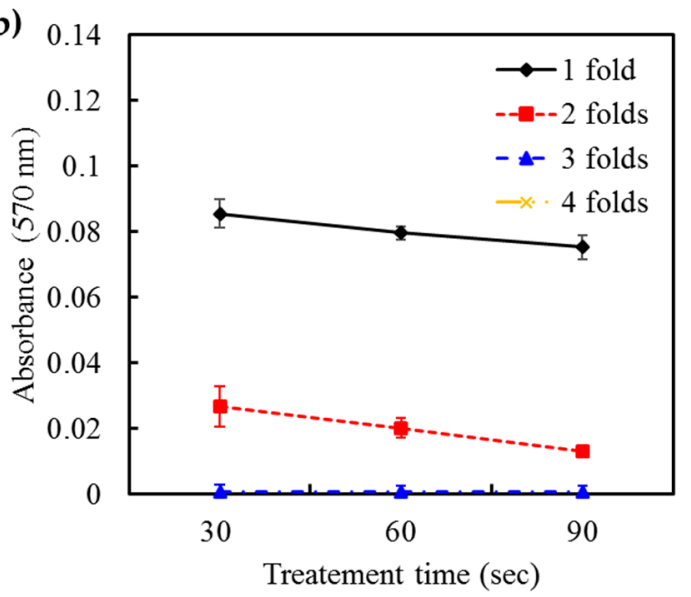

(d)

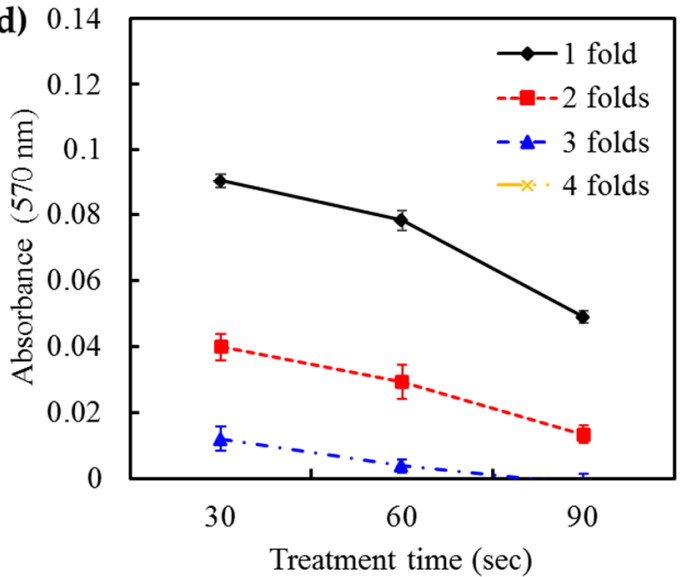

Figure 1. The antimicrobial effect of hypochlorous acid $(\mathrm{HOCl})$ at different volume ratios and treatment times on (a) E. coli; (b) P. gingivalis; (c) E. faecalis; and (d) S. sanguinis. The results were reported in absorbance units. $\mathrm{HOCl}$ showed volume-dependent antibacterial ability against all four species. The antibacterial efficacy of $\mathrm{HOCl}$ was also time-dependent.

\subsubsection{HOCl Durability}

The durability of irrigants is an essential parameter in the evaluation of antimicrobial efficacy. To determine the durability of $\mathrm{HOCl}$, the irrigant was unsealed and left in contact with the air at ambient temperature for 1 or 2 days. Next, the antibacterial activity against the four bacteria was detected. The changes in antimicrobial effectiveness of $\mathrm{HOCl}$ as a function of contact time are presented in Figure 2. The results of $S$. sanguinis were not shown because of undetectable values. $\mathrm{HOCl}$ showed a time-dependent loss of antimicrobial effectiveness when left in direct contact with the air. Interestingly, the statistical analysis showed that a treatment time in the range of 30-90 s did not influence the antimicrobial effectiveness of $\mathrm{HOCl}$ against bacteria. On the other hand, the $\mathrm{pH}$ values of the $\mathrm{HOCl}$ solution after contact with the air for 1 day and 2 days were 6.85 and 6.91, respectively. Both of these values were significantly higher $(p<0.05)$ than the original $\mathrm{pH}$ value of 6.73 . Notably, the $\mathrm{pH}$ approached stability and held at 6.95 for an extended contact time of up to 7 days. 
(a)

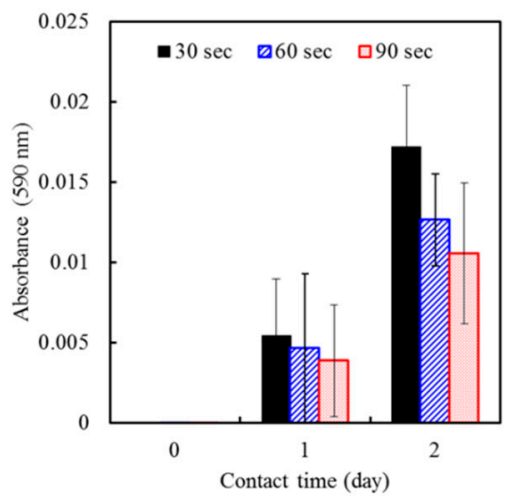

(b)

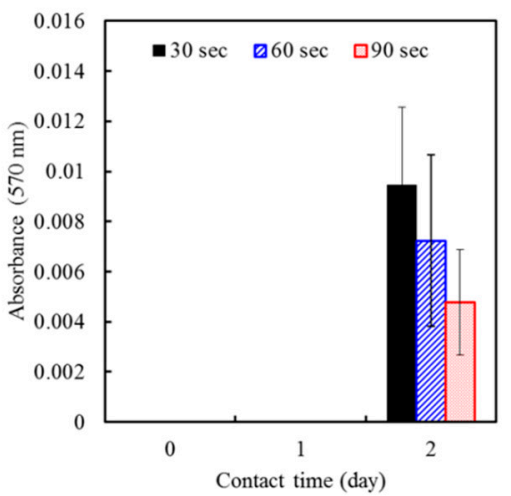

(c)

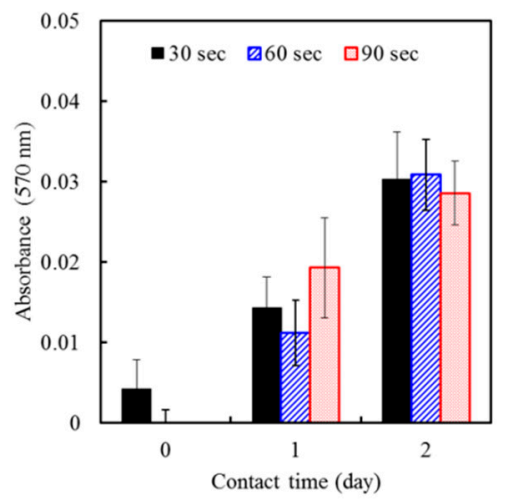

Figure 2. The changes in the antimicrobial effectiveness of $\mathrm{HOCl}$ as a function of contact time with air on (a) E. coli; (b) P. gingivalis; and (c) E. faecalis. The volume ratio of $\mathrm{HOCl}$ to bacterial suspension was 4:1. The results were reported in absorbance units. The duration of air contact adversely affected the antimicrobial activity of $\mathrm{HOCl}$; however, the treatment duration did not have a significant effect.

\subsection{Antibacterial Activities on Titanium Alloy}

\subsubsection{Live/Dead Staining}

Figures 3-6 consistently indicate that all the irrigants cause the majority of bacteria on the titanium alloy surfaces to turn red in the live/dead cell assay when compared with the unirrigated control. This result demonstrated that $\mathrm{HOCl}$ exerted an antibacterial activity that was similar to $\mathrm{NaOCl}$ and $\mathrm{CHX}$.

(a)
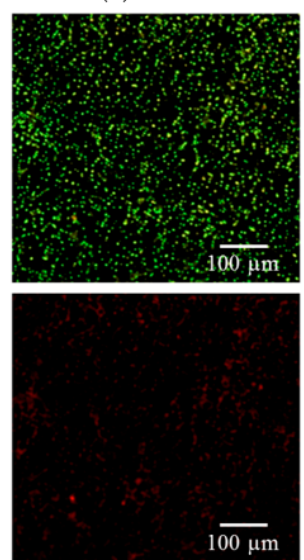

(b)
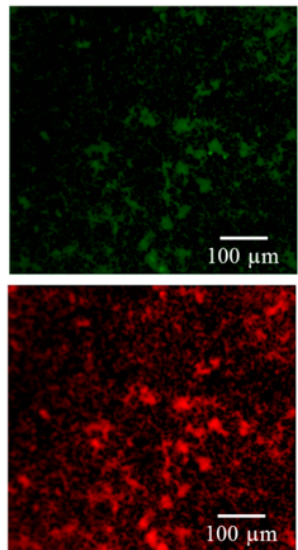

(c)
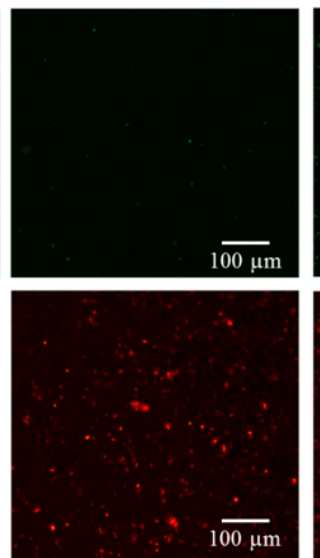

(d)

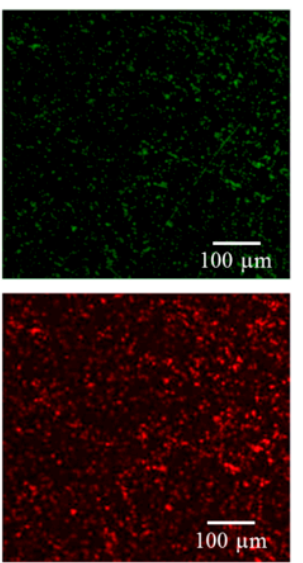

Figure 3. Viability staining of (a) E. coli exposed to (b) $\mathrm{HOCl},(\mathbf{c})$ sodium hypochlorite (NaOCl), and (d) chlorhexidine (CHX). Viable bacteria are labeled green, and dead bacteria are labeled red. Fewer viable E. coli bacteria were found after treatment with the three irrigants. 
(a)
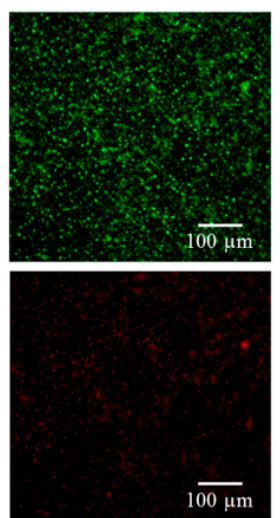

(b)
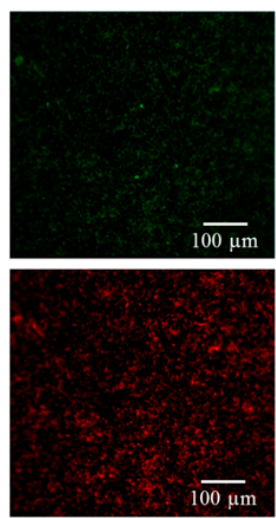

(c)
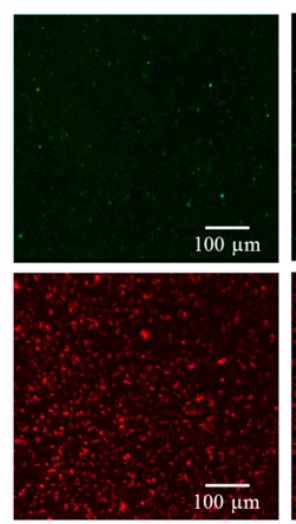

(d)
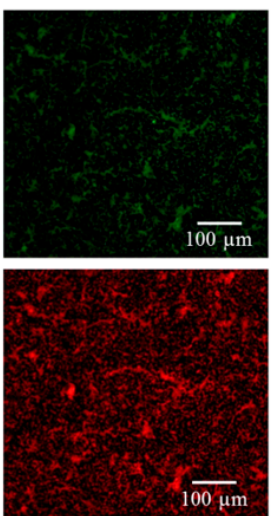

Figure 4. Viability staining of (a) P. gingivalis exposed to (b) $\mathrm{HOCl}$, (c) $\mathrm{NaOCl}$, and (d) $\mathrm{CHX}$. Viable bacteria are labeled green, and dead bacteria are labeled red. The three irrigants induced significant reductions in bacterial numbers when compared with the control.

(a)
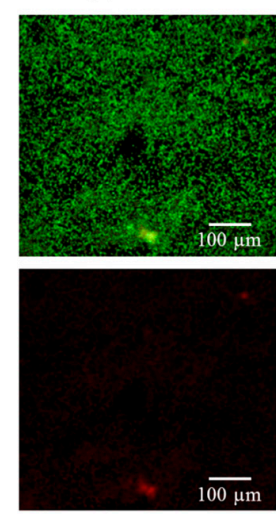

(b)

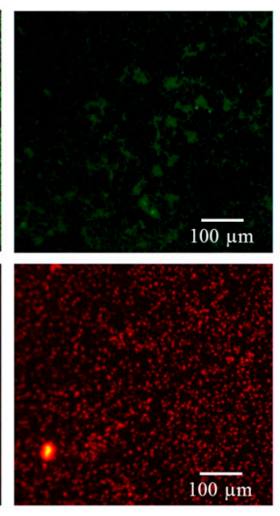

(c)

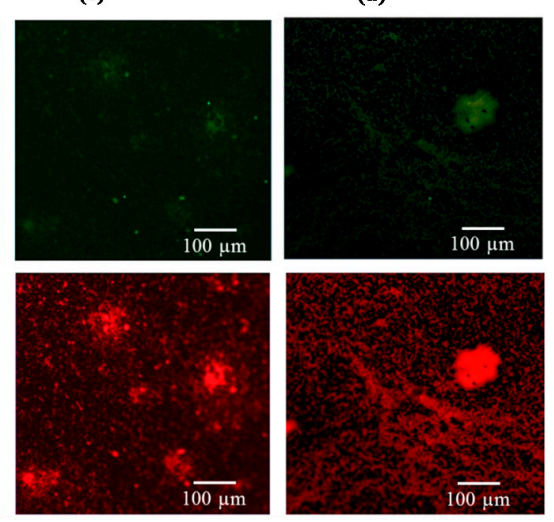

Figure 5. Viability staining of (a) E. faecalis exposed to (b) $\mathrm{HOCl}$, (c) $\mathrm{NaOCl}$, and (d) $\mathrm{CHX}$. Viable bacteria are labeled green, and dead bacteria are labeled red. The dead bacteria in the irrigant-treated groups made up a greater proportion of the total bacteria on the titanium alloy surfaces when compared with the control.

(a)
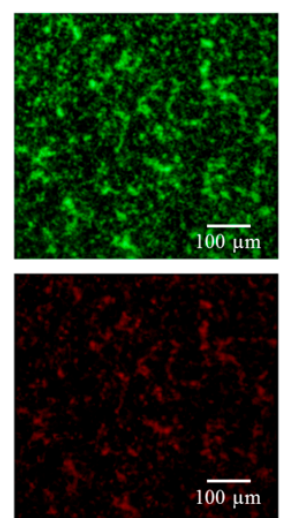

(b)
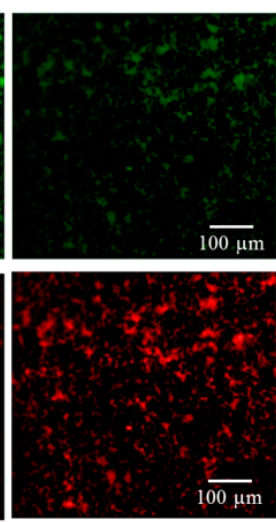

(c)
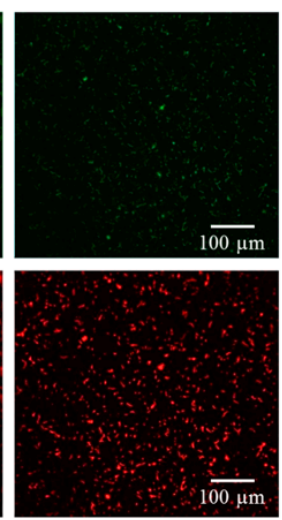

(d)

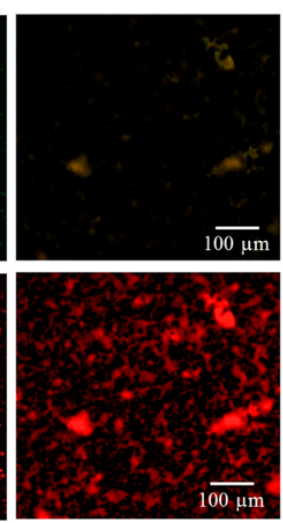

Figure 6. Viability staining of (a) S. sanguinis exposed to (b) $\mathrm{HOCl}$, (c) $\mathrm{NaOCl}$, and (d) $\mathrm{CHX}$. Viable bacteria are labeled green, and dead bacteria are labeled red. An increased amount of dead bacteria was observed after irrigant treatment. 


\subsubsection{SEM Observation}

To clarify the effect of irrigants on the number of bacteria on the titanium alloy surfaces, the surface morphologies of the samples were observed using SEM before and after irrigant treatment. Although the rod-shaped E. coli was contaminated during incubation with the appearance of differently shaped bacteria, the number of E. coli bacteria was appreciably reduced after irrigant treatment (Figure 7). Similarly, the three irrigants effectively reduced the number of the other three bacterial species when compared with the unirrigated control. In contrast to the findings in the HOCl-treated groups, almost a complete removal of bacterial species adhered to the surface was observed after treatment with $\mathrm{NaOCl}$ and CHX.

(a)

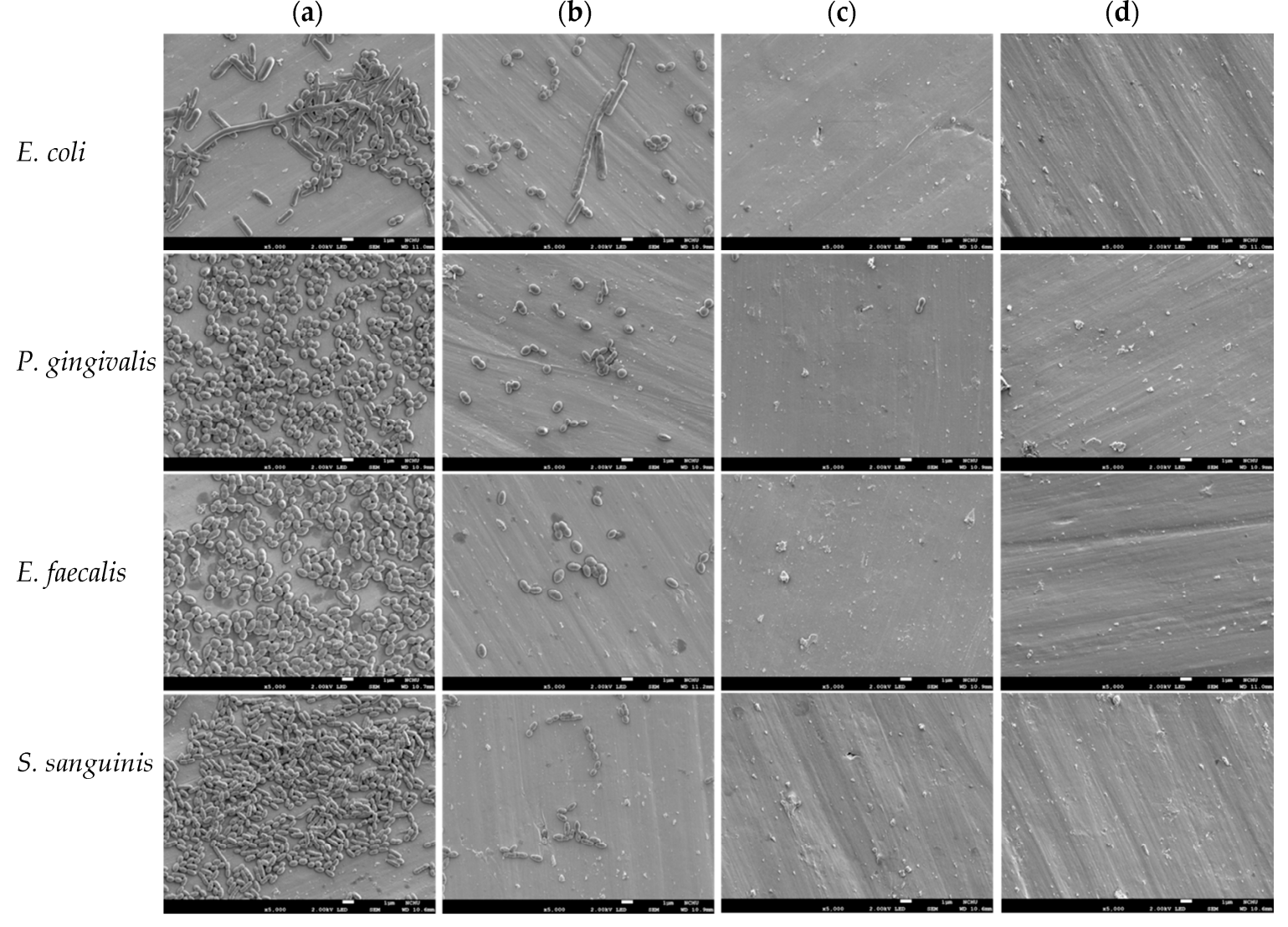

Figure 7. Scanning electron micrographs of (a) the four bacterial species exposed to (b) $\mathrm{HOCl}$, (c) $\mathrm{NaOCl}$, and (d) CHX showed that the three irrigants appreciably reduced the number of bacteria. Almost a complete removal of the bacteria adhered to the surface was observed after treatment with $\mathrm{NaOCl}$ and CHX. Scale bar, $1 \mu \mathrm{m}$.

\subsubsection{AlamarBlue Assay}

To further clarify bacterial viability on the implant surfaces, an alamarBlue assay was used to examine the antimicrobial effectiveness of $\mathrm{HOCl}, \mathrm{NaOCl}$, and $\mathrm{CHX}$. The three irrigants effectively eliminate bacteria (Figure 8). The antimicrobial activity of $\mathrm{HOCl}$ was slightly inferior to $\mathrm{NaOCl}$ and CHX, which is consistent with our SEM observations (Figure 7). 


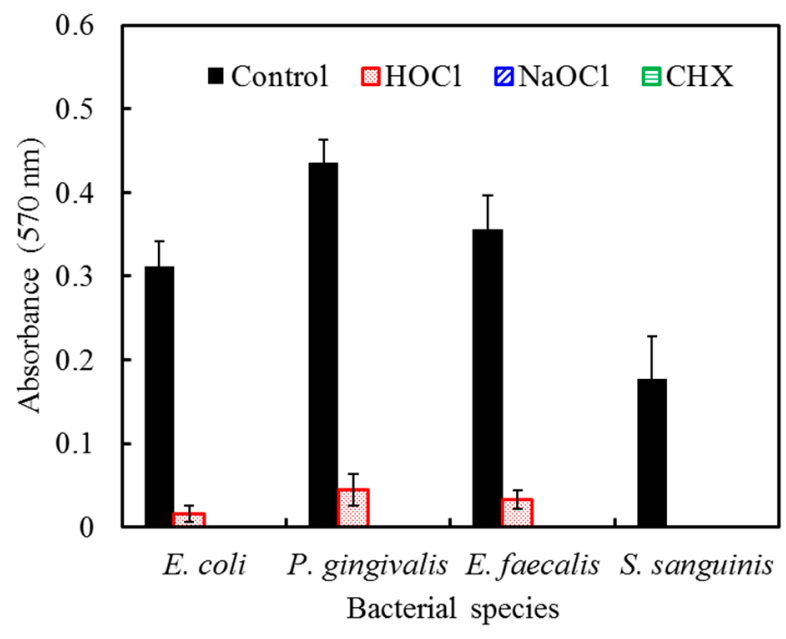

Figure 8. Antimicrobial effectiveness of $\mathrm{HOCl}, \mathrm{NaOCl}$, and $\mathrm{CHX}$ against E. coli, P. gingivalis, E. faecalis, and $S$. sanguinis on titanium alloy surfaces after culture for $24 \mathrm{~h}$. The data were presented as absorbance units. Notably, all the irrigants significantly eliminated bacterial adhesion.

\subsubsection{LPS Detection}

LPS, also termed endotoxin, is the major cell wall component of Gram-negative bacteria, such as E. coli and P. gingivalis. To investigate the removal of biofilms from the titanium alloy surfaces, the amount of residual LPS on the implant surface was examined after treatment with the different antiseptics. Figure 9 shows no significant difference $(p>0.05)$ in residual LPS levels from E. coli after $\mathrm{HOCl}, \mathrm{NaOCl}$, and $\mathrm{CHX}$ treatment for $60 \mathrm{~s}$. In contrast to these findings, $\mathrm{HOCl}$ produced a significant increase $(p<0.05)$ in the removal of LPS from $P$. gingivalis when compared with $\mathrm{NaOCl}$ and $\mathrm{CHX}$.

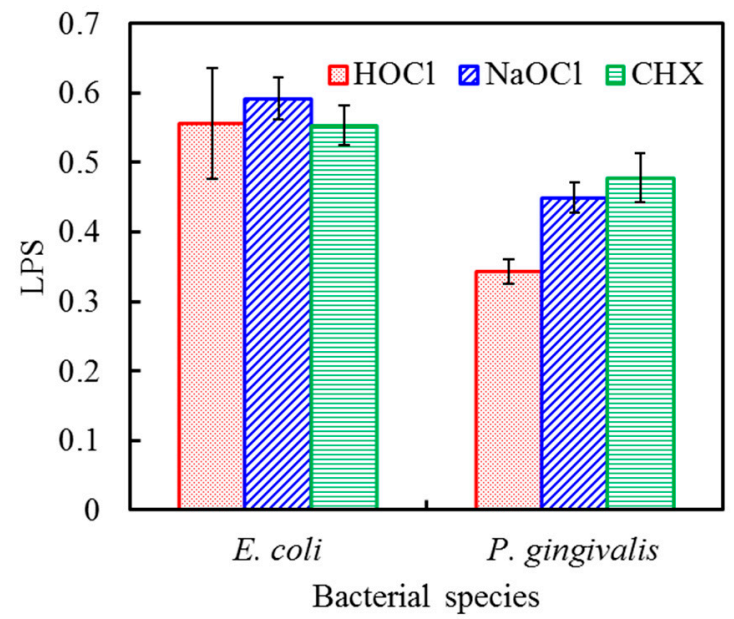

Figure 9. Residual lipopolysaccharide (LPS) levels from E. coli and P. gingivalis on titanium alloy surfaces after $\mathrm{HOCl}, \mathrm{NaOCl}$, and $\mathrm{CHX}$ treatment for $60 \mathrm{~s}$. There was no significant difference in the residual LPS levels from E. coli. However, treatment with $\mathrm{HOCl}$ caused a significant decrease in the LPS from $P$. gingivalis when compared with $\mathrm{NaOCl}$ and $\mathrm{CHX}$.

\section{Discussion}

Implant-associated infections are due to bacterial biofilms that form on the implant surface; thus, the bacterial colonization of implants can never be completely avoided [21]. The possible reasons for biofilm formation include intraoperative contamination, systemic spreading and permanent transcutaneous passages [22]. In this study, four different bacterial species were used to examine the 
efficacy of chemotherapeutic agents. E. coli is commonly used as a Gram-negative model organism. P. gingivalis is associated with periodontitis and also implicated in peri-implantitis [23]. Of the endodontic pathogens, E. faecalis has been extensively studied because this species is frequently found in endodontic infections [24]. S. sanguinis is often present in the human oral cavity and known as a pioneer bacterium of oral biofilms [14]. The most frequently used chemotherapeutic agents for the treatment of endodontic and periodontal infections are $\mathrm{CHX}$ and $\mathrm{NaOCl}$ [25]. Chemical therapy creates only a minimal risk of damage to the titanium implant surface. Nevertheless, in vivo studies have failed to identify one chemotherapeutic agent as the gold standard for implant surface decontamination [26]. The frequently used concentration of commercially available CHX is $0.12 \%$; however, this dose did not achieve a significant reduction in LPS on contaminated titanium surfaces when compared with untreated controls [27]. In a study by Dennison et al. [15], a $0.12 \%$ CHX treatment removed $94.6 \%$ of the LPS from contaminated machined implant surfaces, but only $37.1 \%$ of the LPS was removed from contaminated plasma-sprayed implant surfaces. Thus, CHX was only modestly effective at removing biofilms. In the present study, the high antimicrobial effectiveness and low LPS removal ability of CHX on titanium alloy confirmed the findings from previous studies $[15,27]$.

$\mathrm{NaOCl}$ has a broad spectrum of antimicrobial activity [25]. However, $\mathrm{NaOCl}$ may be harmful because it is extremely alkaline, irritating and cytotoxic at the concentrations typically used [25,27]. The antimicrobial activity of $\mathrm{NaOCl}$ is dependent on the concentration of un-dissociated $\mathrm{HOCl}$ in solution, and the hypochlorite ion $\left(\mathrm{OCl}^{-}\right)$is less effective than un-dissociated $\mathrm{HOCl}$ [25]. Indeed, commercial $\mathrm{NaOCl}$ solutions exhibit less antimicrobial potential than mildly acidic $\mathrm{HOCl}$ solutions within its effective antimicrobial concentration range [28]. Our results showed that $\mathrm{HOCl}$ failed to be equivalent to the efficacy of $\mathrm{NaOCl}$ and $\mathrm{CHX}$ at the same volume and exposure time. In fact, the used concentration of $\mathrm{HOCl}(0.018 \%)$ was much lower than those of $\mathrm{NaOCl}(1.3 \%)$ and $\mathrm{CHX}(0.2 \%)$ even if 4-fold volume was used. A 4:1 volume ratio of $180 \mathrm{ppm}(0.018 \%) \mathrm{HOCl}$ to bacterial solution completely killed all four of the bacterial strains. This level of antimicrobial efficacy was equivalent to the $1: 1$ volume ratio of $1.3 \% \mathrm{NaOCl}$ and $0.2 \% \mathrm{CHX}$, although their absorbance below the detectable range. Our finding on the volume dependence of the antimicrobial activity of $\mathrm{HOCl}$ is consistent with a previous study [25]. According to the literature [24], the treatment time required to eliminate bacteria appreciably depends on the concentration (or volume) and type of irrigant used. A significantly higher concentration of the antiseptic and longer treatment time is required to completely kill bacteria [29].

Pure $\mathrm{HOCl}$ has not been developed as a commercial pharmaceutical formulation presumably because of the challenge of maintaining storage stability [18]. We demonstrated that the antimicrobial efficacy of $\mathrm{HOCl}$ significantly decreased when $\mathrm{HOCl}$ was left in an open environment in contact with the air at ambient temperature. This is a potential problem for the clinical use of $\mathrm{HOCl}$. The dissociation of $\mathrm{HOCl}$ to the less microbicidal $\mathrm{OCl}^{-}$depends on $\mathrm{pH}$. At an approximate $\mathrm{pH}$ of 6, the concentration of $\mathrm{HOCl}$ is optimal and its dissociation is minimal [18,30]. As the $\mathrm{pH}$ increases, more $\mathrm{OCl}^{-}$is formed [31]. $\mathrm{HOCl}$ was reported to have an antimicrobial effect approximately 80-100 times stronger than the $\mathrm{OCl}^{-}$ion [19], which can explain our results that showed a decrease in the antimicrobial activity of $\mathrm{HOCl}$ after contact with the air. Stabilized $\mathrm{HOCl}$ displayed rapid and concentration-dependent activity against clinically relevant microorganisms as long as the effective $\mathrm{pH}$ range was maintained [29]. To stabilize the balanced $\mathrm{HOCl}$ solution, it should be stored in a tightly sealed container. Thus, $\mathrm{HOCl}$ could be a durable antibacterial irrigant in daily clinical use if handled properly.

A critical pathogenic event in the process of biofilm formation is bacterial adhesion on the titanium surface [32]. The effect of residual dead bacteria on the healing process of previously contaminated implants and the extent of bacterial removal required to achieve a successful treatment outcome requires further investigation [1,33]. In the present study, we used a simple grit-blasted titanium alloy to create biofilms for subsequent tests with antimicrobial agents. Based on the preliminary results, we further compared the antibacterial efficacy of $\mathrm{HOCl}, \mathrm{NaOCl}$, and $\mathrm{CHX}$ on titanium alloy surfaces using a 4:1 volume ratio and 60 s exposure time, and focused on the detection of residual LPS. In the case of E. coli, the three antiseptics revealed no significant differences in the levels of residual LPS on 
the titanium alloy surface. The $1.3 \% \mathrm{NaOCl}$ and $0.2 \% \mathrm{CHX}$ solutions demonstrated slightly higher antimicrobial activity than $0.018 \% \mathrm{HOCl}$ in the alamarBlue assay. However, the $0.018 \% \mathrm{HOCl}$ resulted in a greater reduction of LPS from $P$. gingivalis-contaminated titanium alloy surfaces when compared with $1.3 \% \mathrm{NaOCl}$ and $0.2 \% \mathrm{CHX}$. LPS are large molecules that consist of a lipid and an O-antigen-based polysaccharide. $\mathrm{HOCl}$ forms chlorohydrins by attacking the double bonds of unsaturated lipids [34], and chlorohydrins have the potential to damage cell membranes and induce cytolysis [35]. The results of this in vitro study demonstrated that it is possible to significantly reduce biofilm-associated bacterial populations in a clinically relevant time period. However, the mechanism of LPS removal by HOCl requires further investigation.

\section{Materials and Methods}

\subsection{Irrigants and Microorganisms}

The tested irrigant was 180 ppm $(0.018 \%) \mathrm{HOCl}$ liquid (Superclean) kindly donated from Union Biomedical Corporation (New Taipei City, Taiwan). Two commonly used irrigants, $1.3 \% \mathrm{NaOCl}$ (Shimakyu's Pure Chemical, Osaka, Japan) and $0.2 \%$ chlorhexidine gluconate (Panion \& BF Biotech, Taoyuan, Taiwan), were used for comparative purposes. In this study, Gram-negative bacteria strains (Escherichia coli (E. coli, ATCC DH5 ALPHA) and Porphyromonas gingivalis (P. gingivalis, A7436)) and Gram-positive bacteria strains (Enterococcus faecalis (E. faecalis, ATCC 29212) and Streptococcus sanguinis (S. sanguinis, ATCC 10556)) were used. The bacteria were cultivated in Wilkins-Chalgren Anaerobe broth (Oxoid, Hampshire, UK) broth at $37^{\circ} \mathrm{C}$ under anaerobic conditions.

\subsection{Antibacterial Effectiveness of $\mathrm{HOCl}$}

The antibacterial effectiveness of various volumes of $\mathrm{HOCl}$ on bacterial strains was determined using an alamarBlue (Invitrogen, Grand Island, NY, USA) assay that was used for real-time and repeated monitoring of bacterial viability. Volumes of 1, 2, 3, or $4 \mathrm{~mL}$ of $180 \mathrm{ppm} \mathrm{HOCl}$ was added to $1 \mathrm{~mL}$ of a bacterial suspension solution containing approximately 105 colony-forming units (CFU) for 30,60 or 90 s. One $\mathrm{mL}$ of $1.3 \% \mathrm{NaOCl}$ and $0.2 \% \mathrm{CHX}$ were also used according to this method. After the end of the treatment, alamarBlue was added to the test solution and incubated at $37^{\circ} \mathrm{C}$ for $20 \mathrm{~min}$. The solution in each tube was transferred to a new 96-well tissue culture plate. Plates were read in a Sunrise Microtiter reader (Tecan Austria Gesellschaft, Salzburg, Austria) at $570 \mathrm{~nm}$ with a reference wavelength of $600 \mathrm{~nm}$. The results were reported in absorbance units. The number of living bacteria was estimated from the redox reactions between the indicator dye and metabolically active bacteria. The maximum absorption value at $570 \mathrm{~nm}$ is directly proportional to the number of live bacteria. The absorbance results were obtained in nine independent measurements. In addition, $\mathrm{HOCl}$ was unsealed and left in contact with the air for 1 or 2 days at ambient temperature. To examine its durability, $4 \mathrm{~mL}$ of the unsealed $\mathrm{HOCl}$ was then used in the alamarBlue assay to examine changes in antibacterial efficacy. The data provided for each group are the means of nine independent measurements. The $\mathrm{pH}$ values of the unsealed $\mathrm{HOCl}$ solution were measured using a $\mathrm{pH}$ meter (Suntex SP-701, Taipei, Taiwan). The analysis was carried out in three separate sets of experiments.

\subsection{Preparation of Titanium Alloy}

Commercially available 3 mm-thick Ti-6Al-4V alloys (ASTM F136-84; Titanium Industries, Parsippany, NJ, USA) of $10 \times 10 \mathrm{~mm}^{2}$ were selected as substrate material. All samples were wet-ground with 1200-grit SiC abrasive paper (3M Wetordry TriMite 734, St. Paul, MN, USA), ultrasonically cleaned in acetone and ethanol for $20 \mathrm{~min}$, rinsed in deionized water, and then dried in an oven at $60^{\circ} \mathrm{C}$.

\subsection{Live/Dead Staining on Titanium Alloy}

One milliliter of each bacterial suspension at a density of $10^{5} \mathrm{CFU} / \mathrm{mL}$ was placed on the titanium alloy surface in 24 -well culture plates. The samples were incubated at $37^{\circ} \mathrm{C}$ for $24 \mathrm{~h}$ for subsequent 
analyses, including live/dead staining, morphology observation, alamarBlue assay, and LPS detection. The choice of $24 \mathrm{~h}$ was based on the time interval for the stationary phase of microbial growth curves. For the live/dead fluorescent stain, the samples were washed twice with phosphate buffer solution (PBS, pH 7.4). Next, $\mathrm{HOCl}, \mathrm{NaOCl}$, and $\mathrm{CHX}$ were added to the plates at a volume 4 times that of the bacterial suspension. Samples were allowed to react at room temperature for $60 \mathrm{~s}$. The samples were then washed with deionized water and incubated with the BacLight Live/Dead bacterial viability solution (Molecular Probes, Eugene, OR, USA) for $15 \mathrm{~min}$. The staining reagent was removed with deionized water, and the bacteria adhered on the specimens were visualized using a ZEISS AXioskop2 microscope (Carl Zeiss, Thornwood, NY, USA) at $200 \times$ magnification.

\subsection{Morphology Observation on Titanium Alloy}

After exposure to the irrigants, the samples were washed three times with PBS and fixed in $2 \%$ glutaraldehyde (Sigma, St. Louis, MO, USA). The samples were then dehydrated using a graded ethanol series for $20 \mathrm{~min}$ at each concentration. The dried samples were mounted on stubs, coated with a gold layer, and viewed using scanning electron microscopy (SEM; JEOL JSM-7800F, Tokyo, Japan).

\subsection{AlamarBlue Assay on Titanium Alloy}

After treatment of the bacteria with irrigants, the solution was discarded and the plate was filled with alamarBlue reagent. The assay was performed as previously stated in the Methods section. The data shown are the means from fifteen parallel experiments.

\subsection{LPS Detection on Titanium Alloy}

After the irrigants reacted with the bacterial solutions and samples were washed with PBS twice, the remaining LPS concentrations on the substrates were quantified using a ToxinSensor chromogenic Limulus Amebocyte Lysate endotoxin assay kit (GenScript, Piscataway, NJ, USA) according to the manufacturer's instructions. Five replicates were carried out for each group, and the results are expressed as the mean \pm standard deviation.

\subsection{Statistical Analysis}

All the results are expressed as the mean \pm standard derivation for the total number of replicate experiments indicated unless otherwise stated. A one-way analysis of variance (ANOVA) was used to evaluate significant differences between the means. Scheffe's multiple comparisons were used to determine the significance of the standard deviations between the sample measurements under different experimental conditions. The result was considered statistically significant when the $p$-value was less than 0.05 .

\section{Conclusions}

Within the limitations of this in vitro model, $\mathrm{HOCl}$ is effective for cleaning biofilm-contaminated implant surfaces and has the potential to be an antiseptic for peri-implantitis treatment. These results suggest that the efficacy of $\mathrm{HOCl}$ is equivalent to $\mathrm{NaOCl}$ and $\mathrm{CHX}$. The concentration of $\mathrm{HOCl}(0.018 \%)$ was lower than those for $\mathrm{NaOCl}(1.3 \%)$ and $\mathrm{CHX}(0.2 \%)$ but still showed efficacy against the four bacterial species. Notably, $\mathrm{HOCl}$ was superior to the other antiseptics in the reduction of residual LPS from P. gingivalis on implant surfaces. However, additional studies, including use of the multispecies biofilm model and screw-shaped implants and other biocompatibility tests, are required prior to the clinical application of $\mathrm{HOCl}$ as an antiseptic.

Author Contributions: Chun-Ju Chen, Chun-Cheng Chen and Shinn-Jyh Ding conceived and designed the experiments; Chun-Ju Chen performed the experiments; Chun-Cheng Chen and Shinn-Jyh Ding analyzed the data; Chun-Cheng Chen and Shinn-Jyh Ding wrote the paper.

Conflicts of Interest: The authors declare no conflict of interest. 


\section{References}

1. Berglundh, T.; Persson, L.; Klinge, B. A systematic review of the incidence of biological and technical complications in implant dentistry reported in prospective longitudinal studies of at least 5 years. J. Clin. Periodontol. 2002, 29, 197-212. [CrossRef] [PubMed]

2. Lang, N.P.; Ptjetursson, B.E.; Tank, K.; Brägger, U.; Egger, M.; Zwahlen, M. A systematic review of the survival and complication rates of fixed partial dentures (FPDs) after an observation period of at least 5 years. II. Combined tooth-implant-supported FPDs. Clin. Oral Implants Res. 2004, 15, 643-653. [CrossRef] [PubMed]

3. Ho, C.C.; Ding, S.J. Novel $\mathrm{SiO}_{2}$ /PDA hybrid coatings to promote osteoblast-like cell expression on titanium implants. J. Mater. Chem. B 2015, 3, 2698-2707. [CrossRef]

4. Hegedús, C.; Ho, C.C.; Csík, A.; Biri, S.; Ding, S.J. Enhanced physicochemical and biological properties of ion-implanted titanium using electron cyclotron resonance ion sources. Materials 2016, 9, 25. [CrossRef]

5. Mombelli, A.; Lang, N.P. The diagnosis and treatment of peri-implantitis. Periodontol. 2000 1998, 17, 63-76. [CrossRef] [PubMed]

6. Renvert, S.; Polyzois, I.; Claffey, N. Surgical therapy for the control of periimplantitis. Clin. Oral Implants Res. 2012, 23, 84-94. [CrossRef] [PubMed]

7. Furst, M.M.; Salvi, G.E.; Lang, N.P.; Persson, G.R. Bacterial colonization immediately after installation on oral titanium implants. Clin. Oral Implants Res. 2007, 18, 501-508. [CrossRef] [PubMed]

8. Charalampakis, G.; Ramberg, P.; Dahlén, G.; Berglundh, T.; Abrahamsson, I. Effect of cleansing of biofilm formed on titanium discs. Clin. Oral Implants Res. 2015, 26, 931-936. [CrossRef] [PubMed]

9. Zablotsky, M.H.; Diedrich, D.L.; Meffert, R.M. Detoxification of endotoxin-contaminated titanium and hydroxyapatite-coated surfaces utilizing various chemotherapeutic and mechanical modalities. Implant Dent. 1992, 1, 154-158. [CrossRef] [PubMed]

10. Ntrouka, V.I.; Slot, D.E.; Louropoulou, A.; Van der Weijden, F. The effect of chemotherapeutic agents on contaminated titanium surfaces: A systematic review. Clin. Oral Implants Res. 2011, 22, 681-690. [CrossRef] [PubMed]

11. Teughels, W.; Van Assche, N.; Sliepen, I.; Quirynen, M. Effect of material characteristics and or surface topography on biofilm development. Clin. Oral Implants Res. 2006, 17, 68-81. [CrossRef] [PubMed]

12. Renvert, S.; Roos-Jansäker, A.M.; Claffey, N. Non-surgical treatment of peri-implant mucositis and peri-implantitis: A literature review. J. Clin. Periodontol. 2008, 35, 305-315. [CrossRef] [PubMed]

13. Ntrouka, V.; Hoogenkamp, M.; Zaura, E.; van der Weijden, F. The effect of chemotherapeutic agents on titanium-adherent biofilms. Clin. Oral Implants Res. 2011, 22, 1227-1234. [CrossRef] [PubMed]

14. Bürgers, R.; Witecy, C.; Hahnel, S.; Gosau, M. The effect of various topical peri-implantitis antiseptics on Staphylococcus epidermidis, Candida albicans, and Streptococcus sanguinis. Arch. Oral Biol. 2012, 57, 940-947. [CrossRef] [PubMed]

15. Dennison, D.K.; Huerzeler, M.B.; Quinones, C.; Caffesse, R.G. Contaminated implant surfaces: An in vitro comparison of implant surface coating and treatment modalities for decontamination. J. Periodontol. 1994, 65, 942-948. [CrossRef] [PubMed]

16. Stewart, P.S.; Franklin, M.J. Physiological heterogeneity in biofilms. Nat. Rev. Microbiol. 2008, 6, $199-210$. [CrossRef] [PubMed]

17. Lapenna, D.; Cuccurullo, F. Hypochlorous acid and its pharmacological antagonism: An update picture. Gen. Pharmacol. 1996, 27, 1145-1147. [CrossRef]

18. Wang, L.; Bassiri, M.; Najafi, R.; Najafi, K.; Yang, J.; Khosrovi, B.; Hwong, W.; Barati, E.; Belisle, B.; Celeri, C.; et al. Hypochlorous acid as a potential wound care agent. Part I. Stabilized hypochlorous acid: A component of the inorganic armamentarium of innate immunity. J. Burns Wounds 2007, 6, 65-79.

19. Rossi-Fedele, G.; Guastalli, A.R.; Doğramacı, E.J.; Steier, L.; De Figueiredo, J.A.P. Influence of pH changes on chlorine containing endodontic irrigating solutions. Int. Endod. J. 2011, 44, 792-799. [CrossRef] [PubMed]

20. Mainnemare, A.; Megarbane, B.; Soueidan, A.; Daniel, A.; Chapple, I.L.C. Hypochlorous acid and taurine-N-monochloramine in periodontal diseases. J. Dent. Res. 2004, 83, 823-831. [CrossRef] [PubMed]

21. Quirynen, M.; de Soete, M.; van Steenberghe, D. Infectious risks for oral implants: A review of the literature. Clin. Oral Implants Res. 2002, 13, 1-19. [CrossRef] [PubMed] 
22. Winkel, A.; Dempwolf, W.; Gellermann, E.; Sluszniak, M.; Grade, S.; Heuer, W.; Eisenburger, M.; Menzel, H.; Stiesch, M. Introducing a semi-coated model to investigate antibacterial effects of biocompatible polymers on titanium surfaces. Int. J. Mol. Sci. 2015, 16, 4327-4342. [CrossRef] [PubMed]

23. Pier-Francesco, A.; Adams, R.J.; Waters, M.G.J.; Williams, DW. Titanium surface modification and its effect on the adherence of Porphyromonas gingivalis: An in vitro study. Clin. Oral Implants Res. 2006, 17, 633-637. [CrossRef] [PubMed]

24. Chau, N.P.T.; Chung, N.H.; Jeon, J.G. Relationships between the antibacterial activity of sodium hypochlorite and treatment time and biofilm age in early Enterococcus faecalis biofilms. Int. Endod. J. 2015, 48, 782-789. [CrossRef] [PubMed]

25. Gomes, B.P.F.A.; Ferraz, C.C.R.; Vianna, M.E.; Berber, V.B.; Teixeira, F.B.; Souza-Filho, F.J. In vitro antimicrobial activity of several concentrations of sodium hypochlorite and chlorhexidine gluconate in the elimination of Enterococcus faecalis. Int. Endod. J. 2001, 34, 424-428. [CrossRef] [PubMed]

26. Claffey, N.; Clarke, E.; Polyzois, I.; Renvert, S. Surgical treatment of peri-implantitis. J. Clin. Periodontol. 2008, 35, 316-332. [CrossRef] [PubMed]

27. Zablotsky, M.H.; Wittrig, E.E.; Diedrich, D.L.; Layman, D.L; Meffert, R.M. Fibroblastic growth and attachment on hydroxyapatite-coated titanium surfaces following the use of various detoxification modalities. Part II: Contaminated hydroxyapatite. Implant Dent. 1992, 1, 195-202. [CrossRef] [PubMed]

28. Ingle, J.I.; Bakland, L.; Baumgartner, J. Ingle's Endodontics, 6th ed.; BC Decker Inc.: Hamilton, ON, Canada, 2008; pp. 997-998.

29. Gera, I. The bacterial biofilm and the possibilities of chemical plaque control: Literature review. Fogorv. Szle. 2008, 101, 91-99.

30. Rutala, W.A.; Weber, D.J. Uses of inorganic hypochlorite (bleach) in health-care facilities. Clin. Microbiol. Rev. 1997, 10, 597-610. [PubMed]

31. Hoffman, P.N.; Death, J.E.; Coates, D. The stability of sodium hypochlorite solutions. In Disinfectants: Their Use and Evaluation of Effectiveness; Collins, C.H., Allwood, M.C., Bloomfield, S.F., Fox, A., Eds.; Academic Press: London, UK, 1981; pp. 77-83.

32. Gallo, J.; Holinka, M.; Moucha, C.S. Antibacterial surface treatment for orthopaedic implants. Int. J. Mol. Sci. 2014, 15, 13849-13880. [CrossRef] [PubMed]

33. Mombelli, A. Microbiology and antimicrobial therapy of peri-implantitis. Periodontol. 2000 2002, 28, 177-189. [CrossRef] [PubMed]

34. Pullar, J.M.; Vissers, M.C.M.; Winterbourne, C.C. Living with a killer: The effects of hypochlorous acid on mammalian cells. IUBMB Life 2000, 50, 259-266. [CrossRef] [PubMed]

35. Spickett, C.M.; Jerlich, A.; Panasenko, O.M.; Arnhold, J.; Pitt, A.R.; Stelmaszynska, T.; Schaur, R.J. The reactions of hypochlorous acid, the reactive oxygen species produced by myeloperoxidase, with lipids. Acta Biochim. Pol. 2000, 47, 889-899. [PubMed]

(C) 2016 by the authors; licensee MDPI, Basel, Switzerland. This article is an open access article distributed under the terms and conditions of the Creative Commons Attribution (CC-BY) license (http://creativecommons.org/licenses/by/4.0/). 